\title{
Effect of three animal models of inflammation on nerve fibres in the synovium
}

\author{
Paul I Mapp, David A Walsh, Neil E Garrett, Bruce L Kidd, Simon C Cruwys, \\ Julia M Polak, David R Blake
}

\begin{abstract}
Objectives-Both sensory and sympathetic nerve fibres are depleted in the synovium in rheumatoid arthritis (RA). The hypothesis that the induction of an inflammatory response in the synovium is capable of causing depletion of nerve fibres was tested.

Methods-To investigate this phenomenon experimental arthritis in the rat was induced by three different methods and the synovium was examined for evidence of nerve depletion by immuocytochemistry.

Results-In a synovitis induced by latex spheres, a mainly macrophage foreign body type reaction, no nerve depletion was seen. In contrast both in an antigeninduced and a hydrogen peroxide-induced model of arthritis nerve fibre depletion was observed. This appeared to affect sensory and sympathetic nerve fibres equally. Nerve fibre depletion was only seen in areas of inflammatory cell infiltration indicating that a mixed lymphocyte and macrophage population of cells may be necessary for this effect.

Conclusions-An inflammatory response, containing lymphocytes and macrophages, in the synovium is capable of the depletion of the finely myelinated and unmyelinated neuropeptide-containing nerves.
\end{abstract}

(Ann Rheum Dis 1994; 53: 240-246)

Inflammation Group, ARC Building, Royal London Hospital Medical College, London, United Kingdom

P I Mapp

DA Walsh*

N E Garrett

B L Kidd

$S$ Cruwys

D R Blake

Department of

Histochemistry, *

Royal Postgraduate

Medical School,

Hammersmith

Hospital, London,

United Kingdom

J M Polak

Correspondence to:

Dr P I Mapp,

Inflammation Group, ARC

Building, London Hospital

Medical College,

Medical College,

W1 2AD, United Kingdom.

Accepted for publication

8 December 1993 inflammation derives from experiments which have been conducted in normal animals under acute conditions and its relevance to chronic inflammation remains uncertain. We consider that in acute inflammation interactions between the nervous system and the vasculature, such as the wheal and flare response, and interactions with cells of the immune system, leading both to priming and activation, are appropriate protective responses to acute tissue injury. A loss of these protective responses due to nerve fibre depletion may contribute to the failure of resolution in chronic inflammation. ${ }^{3}$

The localisation of neuropeptide-containing sensory and sympathetic nerves in the normal human $^{89}$ and rat synovium ${ }^{10}$ have been described. However, in the chronically inflamed human synovium an absence of nerves adjacent to the joint space and a depletion of nerves in the deeper synovium have been demonstrated. ${ }^{8} 911$

We proposed that depletion of nerve fibres is associated with chronic synovial inflammation and can be induced by a variety of stimuli. We have further investigated the depletion of nerve fibres in the synovium by the induction of arthritis in the rat using three different models of inflammation: (1) Hydrogen peroxideinduced inflammation, using glucose oxidase to generate hydrogen peroxide in situ from endogenous glucose. The model is one of acute tissue damage from the hydrogen peroxide which gives rise to a rapid polymorphonuclear leucocyte response, followed by macrophage and lymphocyte recruitment, reaching a peak at seven days and resolving quickly thereafter; (2) Synovitis induced by the injection of latex spheres. This model induces a foreign body type mild synovitis with the recruitment of macrophages and few, if any, lymphocytes; (3) A synovitis induced by the formation of immune complexes within the joint. Animals are systemically sensitised to an antigen, methylated bovine serum albumin, in Freunds adjuvant and subsequently challenged by injection into the joint of the antigen alone.

Nerve fibres were then localised by immunocytochemistry. A pan-neuronal marker, PGP 9.5, was used to demonstrate all types of nerve fibre. The fibres were subdivided into sensory and sympathetic on the basis of their neuropeptide content. Substance P and calcitonin-gene related peptide (CGRP) were used as sensory neuronal markers. The $C$ flanking peptide of neuropeptide $\mathrm{Y}$ (CPON) was used as a marker of postganglionic sympathetic neurones.

\section{Materials and methods}

GLUCOSE OXIDASE MODEL

Hydrogen peroxide-mediated monoarthritis was induced in rats as previously described by 
Dabbagh et al. ${ }^{12}$ One hundred $\mu \mathrm{g}$ of glucose oxidase, linked to polyethylene glycol to improve retention in the joint (Sigma Chemical Co), in $100 \mu$ l of sterile saline was injected into the right knee joint-space of male Wistar rats to induce a hydrogen peroxide-mediated inflammatory reaction. The animals were killed seven days after the injection. Specimens of the rat knees, on both sides, were obtained at the end of the experiment.

LATEX SPHERES MODEL

A synovitis was induced by the injection of 100 $\mu l$ of a $1 \%$ suspension of latex beads (Sigma Chemical Co) in sterile saline into the right knee joint. The latex beads had a mean(SD) particle diameter of $11.9(1.9) \mu \mathrm{m}$. The animals were sacrified 20 days after the injection.

METHYLATED BOVINE SERUM ALBUMIN MODEL Immune monoarthritis was induced as previously described by Brackert $\mathrm{z}^{13}$ in the mouse and modified by van Noorden ${ }^{14}$ for the rat.

Rats were sensitised to methylated bovine serum albumin (mBSA) by multiple subcutaneous injection (4-6 times) of the antigen $(5 \mathrm{mg} / \mathrm{ml}, 0.5 \mathrm{ml}$ in total) in Freunds complete adjuvant on days 0 and 7 . The arthritis was then induced on day 21 by a single injection of $100 \mu \mathrm{l}$ of $5 \mathrm{mg} / \mathrm{ml} \mathrm{mBSA}$ in sterile saline into the right knee joint. Animals were then sacrified 21 days after the induction of the arthritis.

\section{TISSUE PROCESSING}

Knees were fixed by intra-articular injection of $0.1 \mathrm{ml}$ of Zamboni's fluid, ${ }^{15}$ a buffered picric acid/formaldehyde solution, and subsequent immersion fixation for a further six hours. This fixative penetrates rapidly and retains small peptides, such as neuropeptides, in situ. Washing was carried out for five days in phosphate-buffered saline $(0 \cdot 1 \mathrm{M}, \mathrm{pH} 7 \cdot 6)$ containing $15 \%$ sucrose and $0.01 \%$ sodium azide. The knees were then placed on cryostat corks and snap frozen in melting isopentane and stored at $-70^{\circ} \mathrm{C}$ until further use. Frozen

Table 1 Characterisation of the antibodies employed in neuronal staining

\begin{tabular}{|c|c|c|c|c|c|c|c|}
\hline Antisera & Refs & $S P$ & $N K A$ & $\alpha C G R P$ & Gal & $N P Y$ & CPON \\
\hline $\begin{array}{l}\text { PGP 9.5 } \\
\text { Human }\end{array}$ & $\begin{array}{l}19 \\
20\end{array}$ & + & + & + & + & + & + \\
\hline $\begin{array}{l}\text { SP } \\
\text { synthetic }\end{array}$ & $\begin{array}{l}21 \\
22\end{array}$ & $1 \cdot 0$ & $+1-$ & + & + & + & + \\
\hline $\begin{array}{l}\alpha C G R P \\
\text { rat synthetic }\end{array}$ & $\begin{array}{l}21 \\
22\end{array}$ & + & + & $0 \cdot 1$ & + & + & + \\
\hline $\begin{array}{l}\text { CPON } \\
\text { human synthetic }\end{array}$ & $\begin{array}{l}23 \\
24\end{array}$ & + & + & + & + & 1.0 & + \\
\hline
\end{tabular}

All antibodies were used at a dilution of $1: 10,000$ with the exception of the PGP 9.5 antibody which was diluted to $1: 100,000$.

SP, substance P; NKA, Neurokinin A; CGRP, Calcitonin gene-related peptide; NPY, Neuropeptide Y; CPON, C-flanking peptide of neuropeptide Y.

$+=$ No diminution in immunostaining when exposed to $10 \mathrm{nmol}$ antigen $/ \mathrm{ml}$ of antiserum

$+/-=$ Partial loss of staining at $20 \mathrm{nmol}$ antigen $/ \mathrm{ml}$ antiserum

Values represent the minimum amount of antigen required to abolish immunostaining ( $\mathrm{nmol}$ antigen $/ \mathrm{ml}$ antiserum).

Absorbing antigens were obtained from Peninsular Laboratories, St Helens, UK.
$30 \mu \mathrm{m}$ sections were cut on a cryostat, using a tungsten-carbide knife, mounted on polyL-lysine coated slides ${ }^{16}$ and air dried for two hours before processing for immunostaining. The knee was sectioned sagittally through the mid-line and the area of synovium examined was that immediately adjacent to the meniscus on both sides of the joint.

\section{IMMUNOCYTOCHEMISTRY}

Sections were incubated with primary antisera at optimal titre (see table 1) overnight, in a humid atmosphere at $+4^{\circ} \mathrm{C}$ and then immunostained using the avidin-biotin complex (ABC) method. ${ }^{17}$ The biotinylated second antibody and $\mathrm{ABC}$ complex were part of a Vectastain Elite kit (Vector laboratories, UK). The peroxidase immunoproduct was developed using 3,3' diaminobenzidene tetrahydrochloride (DAB) as the chromogen and was enhanced with the glucose oxidase-nickelDAB method. ${ }^{18}$ The sections were dehydrated, cleared and mounted in DPX (Raymond A Lamb, London, UK). Consecutive sections were stained with Haematoxylin and Eosin to assess the inflammatory response.

\section{ANTISERA}

Well characterised rabbit antisera were employed. The neuropeptide antisera were raised at the Hammersmith Hospital and the PGP 9.5 antiserum was obtained from Ultraclone, Cambridge, UK. The characteristics and further references which determine specificity are shown in table 1. Immunocytochemical controls consisted of liquid phase absorbtion of the peptide antisera with both corresponding, and inappropriate antigens with a similar neuronal localisation. Substitution of primary antisera with nonimmune rabbit serum, omission of goat antirabbit biotinylated immunoglobulins or of the avidin-biotin-peroxidase complex served as negative controls. Since there was a significant cross-reaction between substance $P$ antiserum and another tachykinin, neurokinin $A$, it should be noted that the term tachykinin-like immunoreactivity more correctly describes the immunostaining observed with substance $\mathbf{P}$ antiserum.

CHARACTERISATION OF INFILTRATING CELLS IN THE LATEX MODEL

The cellular infiltrate of the latex was characterised by indirect immunoperoxidase staining with monoclonal antibodies against rat determinants. The antibodies were obtained from Sera Lab, Sussex, UK. The specificities of the antibodies are given in table 2 .

\section{Results}

NORMAL SYNOVIUM

Histology

The normal histology of the rat synovium is well described. It consists of a layer of cells, the intimal cells, which form the boundary 
Table 2 Details of the antibodies used to characterise the cellular infiltrate in the latex spheres model

\begin{tabular}{lll}
\hline Antibody & Specificity & Reference \\
\hline Clone W3/13HLK - & T Lymphocyte/granulocyte marker & 25 \\
Clone OX 33 - & B Lymphocyte marker & 26 \\
Clone OX 42 - & Macrophage/dendritic marker & 27 \\
\hline
\end{tabular}

All antibodies were used at a dilution of $1: 1000$ in an indirect immunoperoxidase technique Negative controls were performed by omission of the primary antibody.

between the joint space and the tissue. This layer may vary in depth from one to four cells. There are gaps between the cells and no evidence of an underlying basement membrane. It overlies a stroma composed mainly of fibrofatty tissue which is perfused by a variable number of blood vessels. Very few cells, other than fibroblasts, were present in the normal sub-intimal tissue.

Nerve supply

PGP 9.5 staining revealed nerve fibres throughout the depth of the synovial tissue.

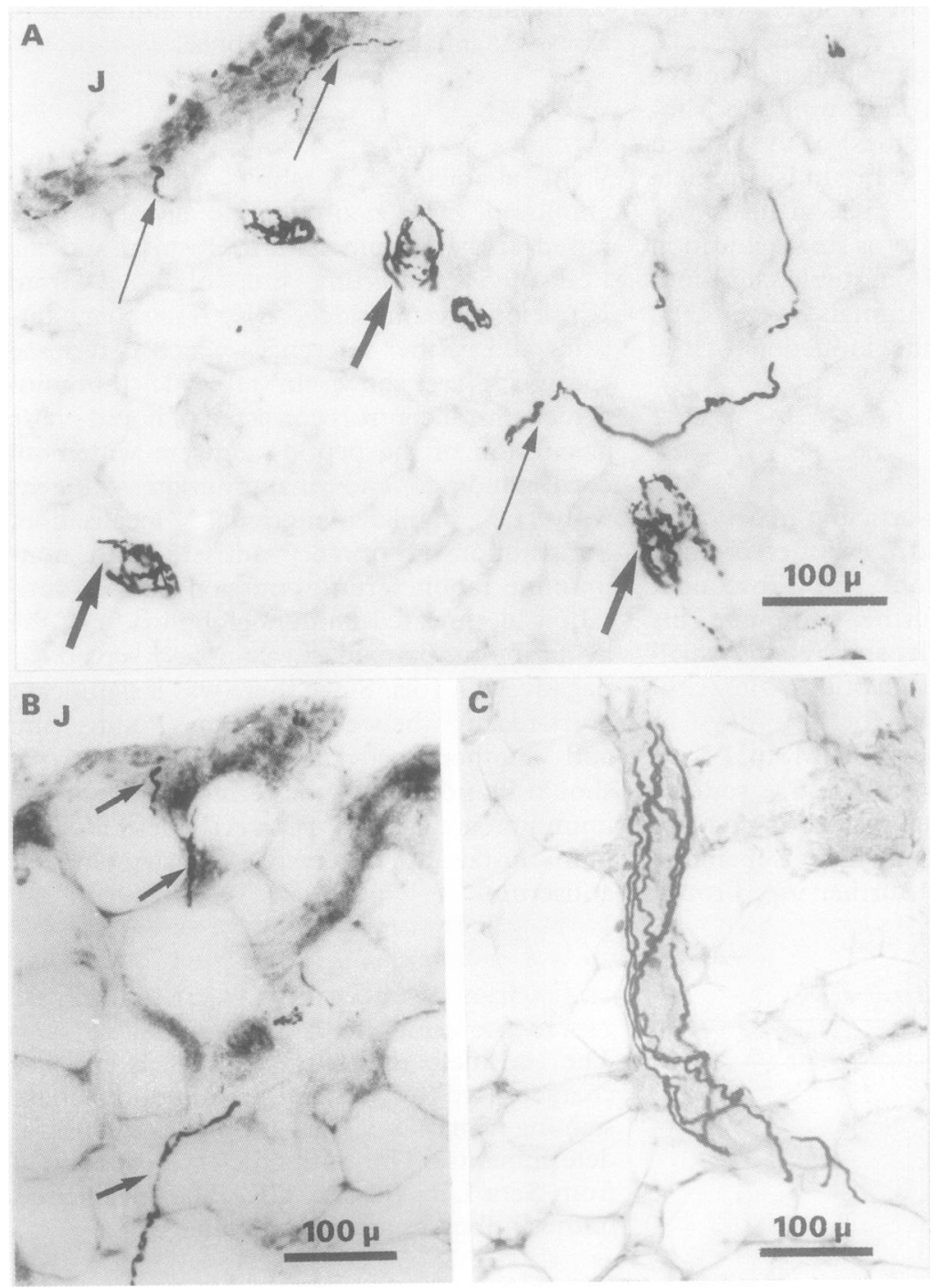

Figure 1A) Rat synovium from a control knee stained for the nerve fibre marker PGP 9.5. Note that free fibres (fine arrows) and perivascular fibres (thick arrows) are present throughout the synovium, including the intimal layer adjacent to the joint space; 1B) Rat synovium from a control knee stained for the sensory nerve fibre marker CGRP, fibres (arrows) are found free in the stroma of the synovium, extending to the joint space (f);1C) Rat synovium from a control knee stained for the postganglionic sympathetic nerve fibre Rat synovium from a control knee stained for the postganglionic sympathetic nerve fibre function of autonomic control of bloodflow.
The nerves were distributed both perivascularly and as free fibres (fig 1A). Nerve fibres were seen not only in the synovial stroma but also extending to the intimal layer. The density of the innervation, judged subjectively, was variable and depended on the level through the knee at which the section was obtained. However, nerve fibres were seen in all sections of the synovium, from all animals. Nerves were consistently present in the synovium adjacent to the meniscus and therefore this area of synovium was selected for assessment.

The sensory innervation, as indicated by staining for CGRP and SP, appeared to be of the same distribution for both markers. Sensory fibres were seen both perivascularly and as free fibres. The fibres extending to the intimal layer of the synovium were positive for these sensory fibre markers (fig 1B). Fewer nerve profiles stained for substance $P$ than CGRP.

Sympathetic innervation as indicated by the staining for the C-flanking peptide of neuropeptide Y (CPON) was exclusively located around blood vessels and was not seen as free fibres (fig 1C).

GLUCOSE OXIDASE-INDUCED SYNOVITIS

\section{Histology}

The histology of the inflammatory response to a single injection of glucose oxidase-PEG has been previously described. ${ }^{12}$ In brief, the initial injection causes destruction of the lining cells of the synovium. In the deeper tissues dilated blood vessels, filled with haemolysed blood are seen. The tissue is filled with neutrophils which are progressively replaced, starting at 4-6 hours, by macrophage/monocytes. At 24 and 48 hours the predominant cell type is the monocyte/ macrophage. As the macrophages mature they migrate towards the synovial layer to clear the cellular debris created by the intrarticular generation of hydrogen peroxide. At seven days the tissue had the typical appearance of a chronic inflammatory response, including monocyte/macrophages, lymphocytes in perivascular accumulations, and a few plasma cells as judged by nuclear morphology. This resolves to a healing and tissue repair stage by day 15 .

\section{Nerve supply}

Nerve depletion was evidenced by the lack of staining for PGP $9 \cdot 5$. Where nerve staining for PGP 9.5 was absent this also corresponded to an absence of all the other peptides for which we tested. (figs 2,3 ).

The nerve depletion was seen in association with inflammatory cell accumulations. In inflamed joints where the synovium were unevenly infiltrated with inflammatory cells, for instance with intense infiltration in the supra-patellar pouch but not in the main body of the joint, only the inflamed areas showed nerve depletion. The initiating injection is given into the supra-patellar space. 


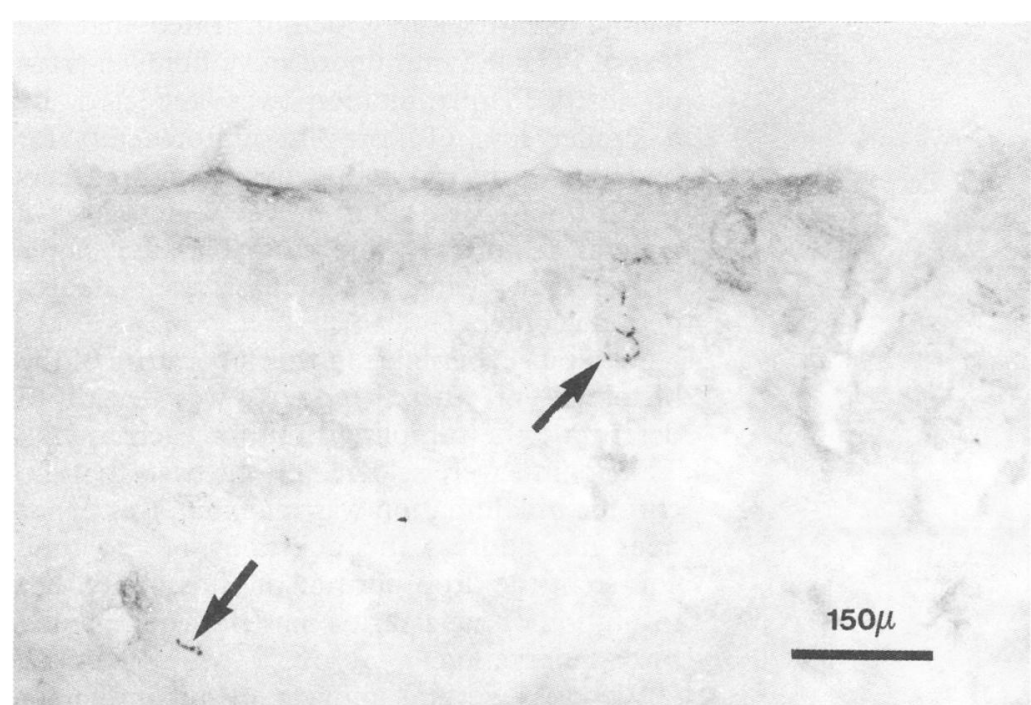

Figure 2 Synovium of a rat knee taken seven days after glucose oxidase treatment and stained in an identical manner to the control knee in fig 3. PGP 9.5-immunoreactive nerve fibres (arrows) are markedly decreased compared with the concurrently stained controls.

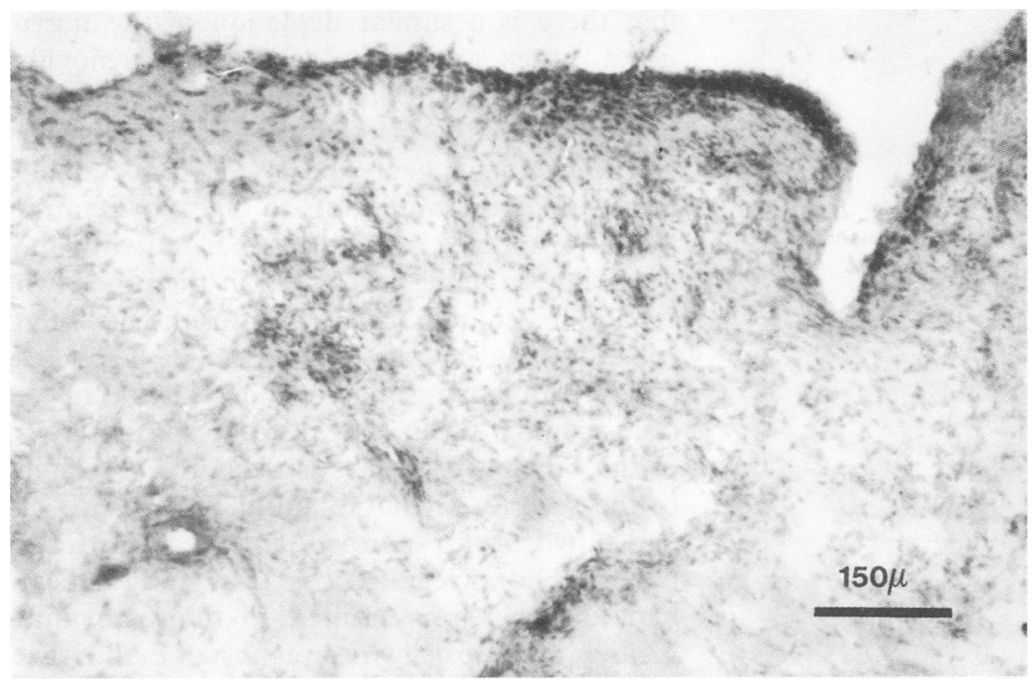

Figure 3 A serial section to fig 2 stained with haematoxylin and eosin. Numerous inflammatory cells are seen in the synovium.

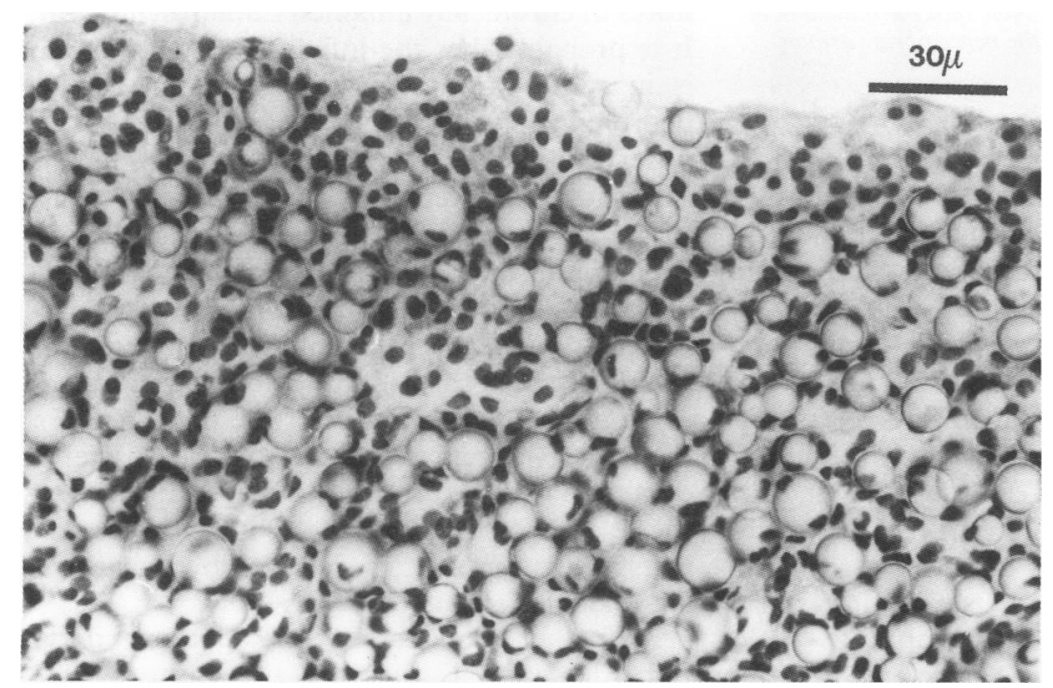

Figure 4 Haematoxylin stained synovium showing the cellular reaction induced by the intra-articular injection of latex spheres.

LATEX-INDUCED SYNOVITIS

Histology

The injection of the latex spheres induced a mild synovitis centred around the spheres themselves. Cells were seen surrounding the latex particles and some cells appeared to have totally ingested the spheres (fig 4). A cellular infiltrate was not seen in areas where the spheres were not present. To characterise the inflammatory infiltrate the sections were stained with monoclonal antibodies to rat cell subsets. The cellular infiltrate failed to stain with $T$ and B lymphocyte markers but was positive for macrophage marker, antibody OX 42 (fig 5).

\section{Nerve supply}

The presence of the spheres and accompanying cellular infiltrate appeared to have no effect on the nerve supply. At day 20, nerve fibres were observed throughout the synovial membrane, including the cells immediately adjacent to the joint space (fig 6).

METHYLATED BSA-INDUCED SYNOVITIS

Histology

The histology of the antigen induced arthritis in the rat has been described previously. ${ }^{28}{ }^{29}$ The formation of immune complexes in the joint space leads to an oedematous swelling of the joint which is maximal at day 5 and continues until at least day 20 . The inflammatory response is characterised by an initial influx of polymorphonuclear neutrophils, progressing from day 14 onwards to cartilage and bone destruction associated with pannus formation.

The inflammatory cell infiltrate in the synovium, of the day 21 animals in this study comprised mainly $\mathrm{T}$ lymphocytes with a few B lymphocytes and plasma cells seen mainly on the outer edges of the lymphocytic infiltrates which appeared to be organised into lymphoid follicles. Macrophages were observed, these were perivascular, free in the stroma of the synovium and contributing to the hyperplasia of the synovial lining layer. Polymorphonuclear leucocytes were seen occasionally in the synovial stroma but more commonly with deposits of fibrin found in the synovial space.

\section{Nerve supply}

The nerve supply, as judged by PGP 9.5 immunostaining, was depleted throughout the synovial membrane (figs 7A, B). Depletion of nerve fibres were most pronounced in areas of intense inflammation while nerve profiles persisted in the less inflamed regions (fig 7C). This pattern of immunostaining was reflected in the lack of immunostaining for the sensory peptides substance $P$ and CGRP and also for the post-ganglionic autonomic marker CPON. Nerve fibre profiles were always seen in the dermal tissue which remained, outside the joint capsule.

\section{Discussion}

The depletion of sensory and sympathetic nerves in relation to joints has been previously noted in human arthritis. ${ }^{8911}$ The effect is most obvious in the synovium closest to the joint space in which there is an almost total 


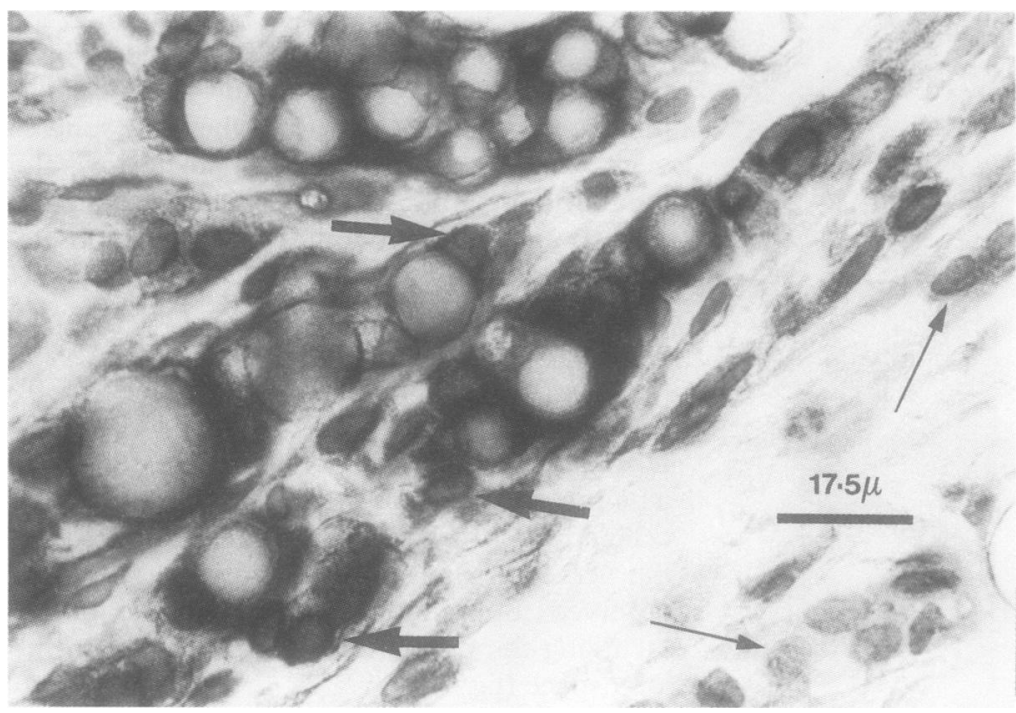

Figure 5 Synovium from an animal injected with latex spheres. The cellular infiltrate is staining positively for the macrophage marker OX 42 (thick arrows). Uninvolved cells (fine arrows) remain unstained.

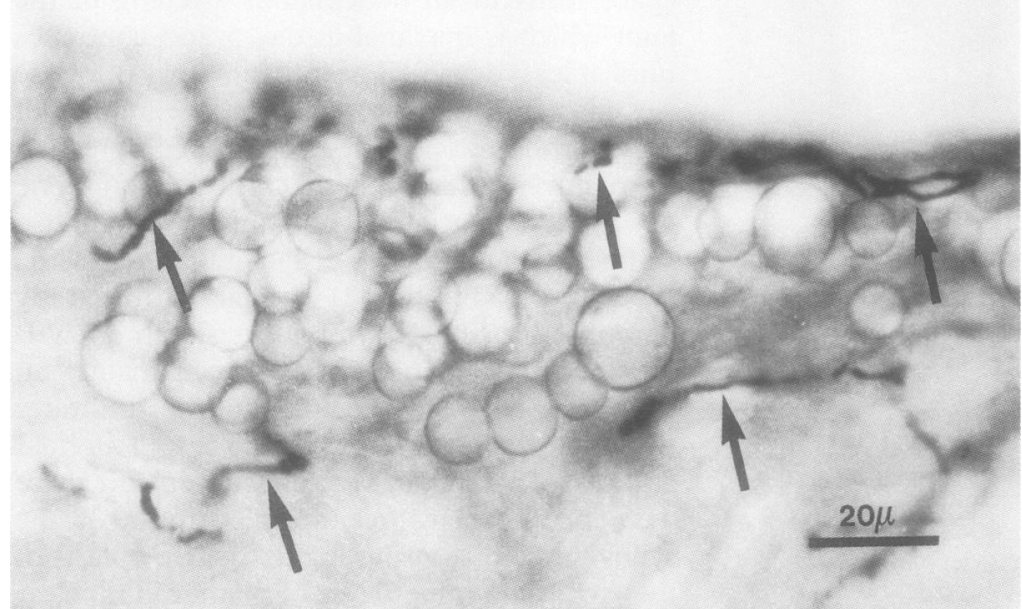

Figure 6 Synovium from the knee of a rat 21 days after injection of latex spheres. The specimen was then stained with the nerve fibre marker PGP 9.5. Note that the induction of a cellular infiltrate by the latex spheres has no apparent effect on the nerve fibres (arrows).

absence of nerves. Deeper in the synovium, adjacent to the joint capsule, some nerve fibres are seen, but only in areas with a mild or absent inflammatory infiltrate. All finely myelinated and unmyelinated nerve fibres were equally affected, this indicating that the inflammatory process is not selective for sensory or sympathetic peptides within the nerves but is a destructive process affecting the nerve fibres themselves. Neuronal PGP 9.5 staining, the constitutive enzyme ubiquitin carboxylterminal hydrolase, ${ }^{30} 31$ is also depleted from the inflamed synovium, suggesting that peripheral nerve fibres axons are absent.

In our experiments nerve fibre assessments were made on a fixed area of the synovium adjacent to menisci to avoid the variability observed between different regions of the synovium in normal animals. Neuronal depletion as indicated by a reduction in PGP 9.5 immunoreactive nerves, was found in two models. Comparison of immunostained and haematoxylin sections demonstrated that the loss of PGP 9.5 immunoreactive fibres in areas of intense inflammation was reflected by a similar loss of fibres immunoreactive for both the sensory and sympathetic markers studied, indicates that nerve depletion is a general feature of fine unmyelinated fibres rather than being specific for their neuropeptide content.

Previous experience in this laboratory of the histology of these models was used to determine the sampling time for each model. Time points were selected on the basis that the chronic inflammation was maximal, this paper does not address the questions of the time course of the drop out nor the possibility that resolution of the arthritis may be accompanied by re-innervation.

We used several models of inflammatory arthritis to discover if the loss of peripheral nerve fibres is a feature common to synovitis in general. We have shown that in both hydrogen peroxide-induced and mBSA-induced arthritis that there is a similar depletion of the nerve fibres. Latex spheres induced a mild synovitis comprising a macrophage infiltrate typical of a foreign body response. However, the presence of the macrophages, which were presumably activated by their attempts to digest or remove the latex spheres, was not associated with the depletion of nerve fibres seen in the other two models. Even after 120 days after the injection (data not shown) no effect of the latex spheres and accompanying macrophages on the nerve fibres could be seen. The distinguishing feature of the other two models is likely to be related to the severity of the inflammation. In mBSA and hydrogen peroxide-induced arthritis polymorphonuclear leucocytes, and latterly lymphocytes, are recruited to the synovium. Neither of these cell type are present in the latex spheres model.

A number of explanations have been put forward for the reduction of peripheral nerve fibres in chronically inflamed human synovium. It is probable that the inflammatory synovium is in some way a cytotoxic environment for neuronal cells. This is supported by our observation that neuronal depletion is associated with regions of inflammatory cells. In joints showing an uneven distribution of cellular infiltrates, inflammation was commonly restricted to the inflammation to the suprapatellar pouch where the initiating injection was given. In these cases nerve fibre depletion was evident in the pouch but not the main body of the joint. Alternatively, the association of nerve depletion with the cellular infiltrate may reflect the fact that factors, such as cytokines or reactive oxygen species, released by those cells are toxic to nerve axons.

A further explanation for apparent nerve fibre depletion is that the synovium is itself proliferating and that this proliferation outstrips the ability of the nervous system to innervate the tissue. However, we consider this to be unlikely since the proliferation index of the synovium in rheumatoid arthritis has been measured by several indices and was found to be very low. ${ }^{32} 33$ 

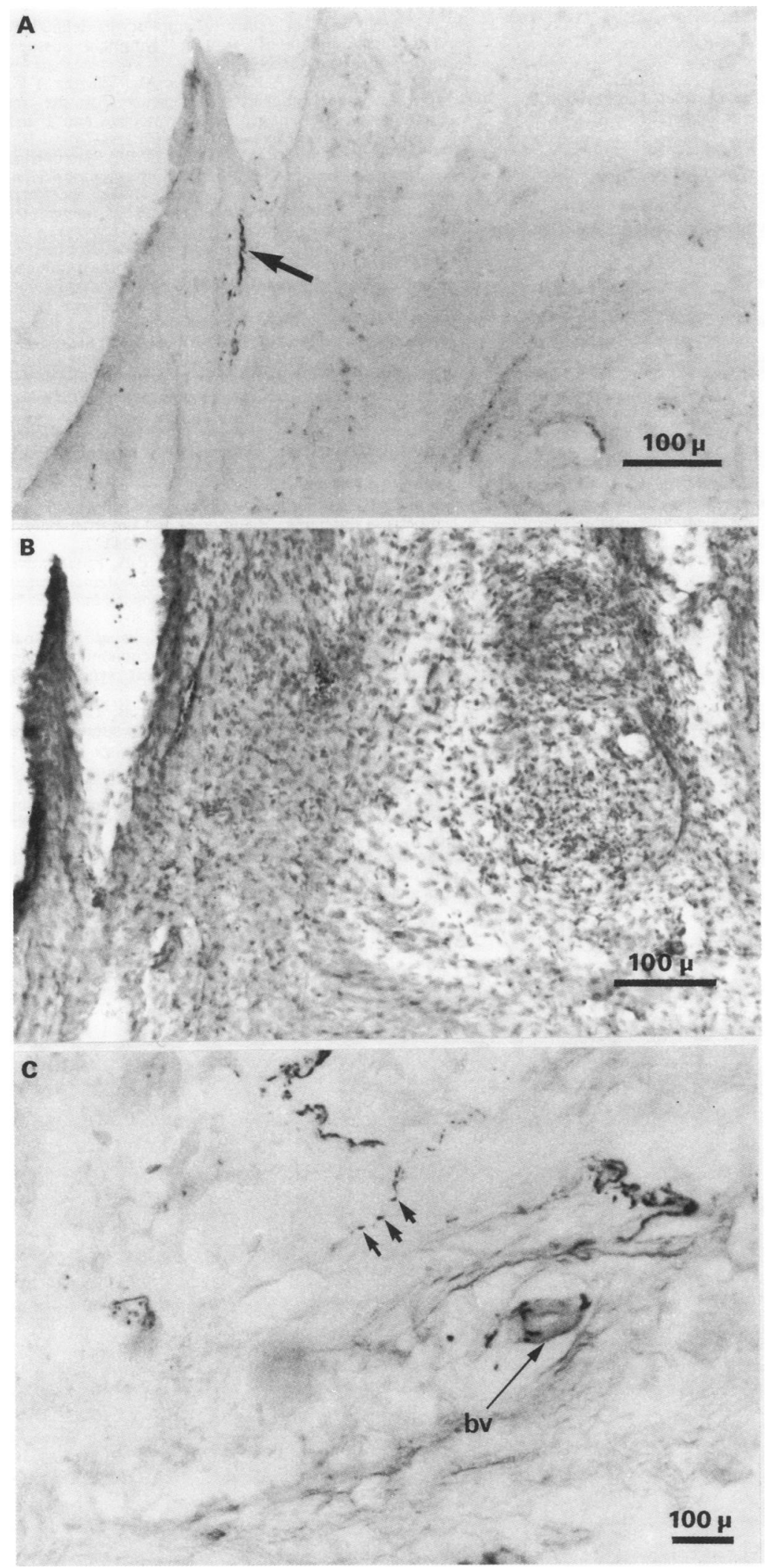

Figure $7 A$ ) Synovium from an animal 21 days after the induction of $m B S A$ arthritis. Few PGP 9.5-immunoreactive nerves are seen (arrow); $7 B) A$ serial section to figure $7 A$ stained with haematoxylin and eosin. Numerous inflammatory cells are seen in the synovium; $7 C$ ) Deep synovium from the same animal as fig $7 A, 21$ days after the induction of $m B S A$ arthritis. Some nerve fibres are seen, mainly in association with blood vessels (BV). Note that even in these nerve fibres there are marked varicosities (arrows).

In acute inflammation, the interactions between the nervous, vascular and immune systems are thought to be protective. In the more aggressive chronic models of arthritis, due to glucose oxidase and methylated BSA, that we induced, nerve fibres are lost in the synovium. Such a loss of nerve fibres has also been reported in the adjuvant-induced model of arthritis (AIA) in the rat. ${ }^{1034}$ It is possible that this loss of nerve fibres may contribute to the persistence of chronic synovial inflammation. Furthermore, since the sensory nervous system is thought to be involved in the tissue healing ${ }^{35}$ it is possible that the depletion of sensory fibres may also delay the onset of the repair process. During wound healing, sensory nerve fibres sprout towards the surface of the wound. ${ }^{36}$ The neuropeptides released from such fibres, such as CGRP, are both angiogenic and vasodilatory. These combined effects would help to combat the ischaemic environment of the inflammatory joint. In support of this, surgical skin flaps which are ischaemic have been shown to have increased survival rates if the sensory nerve supply is intact or the flaps are treated with exogenous CGRP. ${ }^{37}$

In conclusion, we have observed depletion of finely myelinated and umyelinated nerve fibres, using a marker PGP 9.5 which detects all types of nerve fibres, in rat knee synovium chronically inflamed due to glucose oxidase or mBSA, but not that induced by latex spheres. Nerve fibre depletion affected both sensory and sympathetic fibres, which are the finely myelinated and unmyelinated fibres, was predominantly observed in hypercellular regions in the two models exhibiting mixed macrophage/lymphocytic infiltrations. This nerve fibre depletion resembles that seen in human rheumatoid arthritis.

We are grateful to the Oliver Bird Fund of the Nuffield Foundation and the Arthritis and Rheumatism Council for financial support.

1 Brain S D, Williams $\mathrm{T} \mathrm{J}$. Inflammatory oedema induced synergism between calcitonin gene-related peptide and mediators of increased vascular permeability. $\mathrm{Br} f$ Pharmacol 1985; 86: 855-60.

2 Forman J C. Peptides and neurogenic inflammation. Br Med Bull 1987; 43: 386-400.

3 Walsh D A, Wharton D J, Blake D R, Polak J M. Neural and endothelial regulatory peptides, their possible involvement of inflammation. In $\mathcal{f}$ Tissue Reactions 1992; 14: $101-111$.

4 Saria A, Gasmse R, Peterman J, Fischer J A, TheodorssonNorheim E, Lundberg J M. Simultaneous release of several tachykinins and calcitonin gene-related peptide from rat spinal cord slices. Neurosci Letts 1986; 63: from rat

5 Yaksh $T$ L. Substance $P$ release from joint afferent terminals: modulation by opioids. Brain Research 1988; 458: $319-24$.

6 Diez-Guerra F J, Zaidi M, Bevis P, MacIntyre I, Emson P $C$. Evidence for the release of calcitonin gene-related peptide and neurokinin. A from sensory nerve endings in vivo. Neuroscience 1988; 25: 839-46.

7 Kidd B L, Mapp P I, Blake D R, Gibson S J, Polak J M. Neurogenic influences in arthritis. Ann Rheum Dis 1990; 49: 649-52.

8 Mapp P I, Kidd B L, Gibson S J, et al. Substance P-,calcitonin gene-related peptide- and C-flanking peptide of neuropeptide Y- immunoreactive fibres are peptide of neuropeptide Y-immunoreactive fibres are
present in the normal synovium but depleted in patients present in the normal synovium but depleted in patients
with rheumatoid arthritis. Neuroscience 1990; 37: 143-53.

9 Pereria da Silva A, Carmo-Fonseca M. Peptide containing nerves in human synovium: immunohistochemica evidence for decreased innervation in rheumatoid arthritis. F Rheumatol 1990; 17: 1592-9.

10 Konttinen Y T, Rees R, Hukkanen M, et al. Nerves in inflammatory synovium: Immunohistochemical observations on the adjuvant arthritic rat model. $\mathcal{f}$ Rheumatol 1990; 17: 1586-91.

11 Gronblad M, Konntinen Y T, Korkala O, Liesi P, Hukkanen M, Polak J. Neuropeptides in the synovium of patients with rheumatoid arthritis and osteoarthritis. $f$ patients with rheumatoid arth
Rheumatol 1988; 15: 1807-10.

12 Dabbagh A J, Morris C J, Blake D R. Development of an in vivo $\mathrm{H}_{2} \mathrm{O}_{2}$-initiated model of joint inflammation: 1 Histological and systemic studies. Int $\mathcal{f}$ Exp Pathol (in press). 
13 Brackertz D, Mitchell G F, Mackay I R. Antigen-induced arthritis in mice. Arthritis and Rheumatism 1977; 20 841-50.

14 Van Noorden C J F, Smith R E, Resnick D. Cysteine proteinase activity in arthritic rat knee joints and the effects of a selective systemic inhibitor X-Phe-AlaCH $\mathrm{F}$ f Rheumatol 1988; 15: 1525-35.

15 Stefanini M, DeMartino C, Zamboni T. Fixation of ejaculated sperm for electron microscopy. Nature 1967 216: 173-74.

16 Huang S, Gibson S J, Facer P, Gu J, Polak J M. Improved section adhesion for immunocytochemistry using high molecular weight polymers of L-lysine as a slide coating. Histochemistry 1982; 77: 275-9.

$17 \mathrm{Hsu}$ S-M, Raine L, Fanger $H$. Use of avidin-biotinperoxidase complex (ABC) method in immunoperoxidase techniques. F Histochem Cytochem 1981; 29: 577-80.

18 Shu S, Ju G, Fan L. The glucose oxidase-DAB-nickel method in peroxidase histochemistry of the nervous method in peroxidase histochemistry

19 Gulbenkian S, Wharton J, Polak J M. The visualisation of cardiovascular innervation in the guinea pig using an antiserum to protein gene product $9 \cdot 5$ (PGP 9.5). 7 Auton Nerv Syst 1987; 18: 235-47.

20 Lundberg J-M, Alm P, Wharton J, Polak J M. Protein gene product 9.5 (PGP 9.5). A new neuronal marke visualising the whole uterine innervation and pregnancyinduced developmental changes in the guinea pig. Histochemistry 1988; 90: 9-17.

21 Gibson S J, Polak J M, Bloom S R, et al. Calcitonin generelated peptide immunoreactivity in the spinal cord of man and eight other species. $\mathcal{f}$ Neuroscience 1984; 4 man and

22 Merighi A, Polak J M, Gibson S J, Gulbenkian S, Valentino $\mathrm{K}$ L, Perione S M. Ultrastructural studies on calcitonin gene-related peptide-,tachykinins- and somatostatinmmunoreactive neurones in rat dorsal root ganglia: evidence for the colocalisation of different peptides in single secretory granules. Cell Tiss Res 1988; 254: 101-9.

23 Gulbenkian S, Wharton J, Hacker G W, Varndell I M Bloom S R, Polak J M. (1985). Co-localisation of neuropeptide tyrosine (NPY) and its C-terminal flanking peptide (C-PON). Peptides 1985; 6: 1237-43.

24 Marti E, Gibson S J, Polak J M, et al. Ontogeny of peptideand amine containing neurones in motor, sensory, and autonomic regions of rat and human spinal cord, dorsa root ganglia, and rat skin. $f$ Comp Neurol 1987; 266: 332-59.
25 Barclay A N. The localisation of lymphocytes defined by monoclonal antibodies in rat lymphoid tissues. Immunology 1981; 42: 593-600.

26 Woolett G R, Barclay A N, Puklavec M, Williams A G Molecular and antigenic heterogeneity of the rat leucocyte-common antigen from thymocytes and $T$ and B lymphocytes. Eur f Immunol 1985; 15: 168-73.

27 Robinson A P, White T M, Mason D W. Macrophage heterogeneity in the rat as delineated by two monoclonal antibodies MRC OX41 and MRC OX42, the latter recognising complement receptor type 3. Immunology recognising complem

28 Dijkstra C D, Dopp E A, Vogels I C M, van Noorden C J F. Macrophages and dendritic cells in antigen-induced arthritis. Scand f Immunol 1987; 26: 513-23.

29 Griffiths R J. Characterisation and pharmacological sensitivity of antigen arthritis induced by methylated bovine serum albumin in the rat. Agents Actions 1992; 35: 88-95.

30 Day I N, Thompson R J. Molecular cloning of cDNA coding for human PGP 9.5 protein. A novel cytoplasmic marker for neurones and neuroendocrine cells. FEBS-Lett 1987; 210(2): $157-60$

31 Wilkinson K D, Lee K M, Deshpande S, Duerksen-Hughes P, Boss J M, Pohl J. The neuron-specific protein PGP 9.5 is a ubiquitin carboxyl-terminal hydrolase. Science 1989; 246(4930): $670-3$.

32 Coulton L A, Henderson B, Bitensky L, Chayen J. DNA synthesis in the human rheumatoid and non-rheumatoid synovial lining. Ann Rheum Dis 1980; 39: 241-7.

33 Lalor P A, Mapp P I, Hall P A, Revell P A. Proliferative activity of cells in the synovial membrane as demonstrated by the monoclonal antibody Ki67. Rheumatol Int 1987; 7: by the mono 186 .

34 Hukkanen M, Gronblad M, Rees R, et al. Regional distribution of mast cells and peptide-containing nerves in normal and adjuvant arthritic rat synovium. $\mathcal{F}$ Rheumatol 1991; 18: 177-83.

35 Haegerstrand A, Dalsgaard C J, Jonzon B, Larsson $O$ Nilsson J. Calcitonin gene-related peptide stimulates the proliferation of endothelial cells. Neurobiology 1990; 87: 821-8.

36 Hermansson A, Lindblom U, Dalsgaard C-J, Bjorklund H. Sensory reinnervation and sensitivity after superficial skin wound in human patients. Neurosci Lett 1987; 18: 377-82.

37 Kjartansson J, Dalsgaard C-J. Calcitonin gene-related peptide increases the survival of a musculocutaneous critical flap in the rat. Eur $\mathcal{f}$ Pharmacol 1987; 142: 355-8. 